\title{
Interleukin 1 Stimulates Phosphatidylinositol Kinase Activity in Human Fibroblasts
}

\author{
Leslie R. Ballou, ${ }^{\star \star \ddagger}$ Sean C. Barker, ${ }^{\star}$ Arnold E. Postlethwaite, ${ }^{\star \star}$ and Andrew H. Kang**\$ \\ ${ }^{*}$ Research and Medical Service, Veterans Affairs Medical Center and the Departments of ${ }^{\ddagger}$ Medicine and ${ }^{\S}$ Biochemistry, \\ University of Tennessee, Memphis, Tennessee 38163
}

\begin{abstract}
IL-1 mediates multiple cellular immune and inflammatory responses, but little is known of the intracellular biochemical mechanisms involved in IL-1 actions. We studied the effects of IL-1 on phosphatidylinositol (PtdIns) metabolism and confirmed reports indicating that IL-1 does not stimulate increased PtdIns turnover; however, we observed the accumulation of PtdIns-4-phosphate (PtdInsP) in response to IL-1. Using a fibroblast membrane preparation, we were able to detect stimulated PtdInsP accumulation within $10 \mathrm{~s}$ of IL-1 addition. Increased PtdInsP accumulation was due to stimulated PtdIns kinase activity, not the inhibition of PtdInsP hydrolysis by phospholipase(s). PtdIns kinase activity was magnesium dependent, increased as a function of IL-1 concentration, and specifically phosphorylated the D4 position of inositol. Stimulated PtdIns kinase activity could be detected at $10^{-12} \mathrm{M}$ IL-1 in fibroblast membranes, a concentration within the physiological range for IL-1 action; half-maximal activity was reached at $\sim 1^{-10} \mathrm{M}$ IL-1. Heat denaturation of IL-1 or treatment of IL-1 with anti-IL-1 antibody abrogated the IL-1 effect. These findings demonstrate the direct, IL-1-mediated, stimulation of PtdIns kinase. IL-1-stimulated PtdIns kinase activity represents an important physiological regulatory effect by IL-1 as it could control the synthesis and/or maintenance of phosphorylated derivatives of PtdIns which comprise only a very small pool of substrates for the generation of the second messengers inositol 1,4,5-triphosphate and diacylglycerol. (J. Clin. Invest. 1991. 87:299-304.) Key words: cytokine • signal transduction • fibroblast activation $\bullet$ phosphoinositides
\end{abstract}

\section{Introduction}

The term IL-1 refers to a family of proteins, encoded by at least two separate genes, that are produced by a wide variety of cell types in response to a plethora of external stimuli (1). IL-1 has been shown to affect multiple cellular activities both in vivo and in vitro (2), yet the early biochemical events stimulated by IL-1 receptor occupancy or the second messenger molecules induced by IL-1 are not fully understood. The cloning and expression of cDNA for murine (3) and human IL-1 $\alpha$ (4) and $\beta$ (5) have made possible the characterization of high affinity receptors for IL-1 found on the surface of responsive cells including murine and human T cells $(6,7), \mathrm{B}$ cells $(8)$, fibroblasts (9), human neutrophils (10), and human and porcine synovial cells (11-13). Understanding the mechanism(s) by which IL-1

Address correspondence to Leslie R. Ballou, Ph.D., Department of Medicine, Division of Connective Tissue Diseases, University of Tennessee, Memphis, 956 Court Avenue, Room G326, Memphis, TN 38163 .

Received for publication 5 February 1990 and in revised form 20 July 1990.

The Journal of Clinical Investigation, Inc.

Volume 87, January 1991, 299-304 exerts its many biological effects is of great clinical significance since many of those effects are associated with pathogenic processes exemplified by tissue degradation in diseases such as arthritis and diabetes.

Many model systems for receptor-mediated signal transduction involve the activation of a phospholipase C (PLC), ${ }^{1}$ via GTP-binding protein(s), which catalyze the hydrolysis of phosphatidylinositol-4-phosphate (PtdInsP) and phosphatidylinositol-4,5-bisphosphate (PtdIns $\mathrm{P}_{2}$ ) to form inositol triphosphate $\left(\mathrm{IP}_{3}\right)$ and 1,2-diacylglycerol (DAG) (14); $\mathrm{IP}_{3}$ mobilizes $\mathrm{Ca}^{2+}$ from the endoplasmic reticulum $(15,16)$, whereas DAG activates protein kinase $C(17)$. Thus, regulation of the kinases that are responsible for producing and/or replenishing the supply of these phosphoinositides may be important in controlling the production of a variety of second messenger molecules. While mitogens such as $\alpha$-thrombin rapidly induce the hydrolysis of phosphoinositides in hamster fibroblasts (18-20), neither epidermal nor fibroblast growth factor (EGF, FGF) stimulate phosphoinositide breakdown even though both factors possess potent mitogenic activity $(21,22)$. These data suggest that while the activation of PLC may be an essential step for those factors whose receptors are coupled to PLC (23), it is not required for the mitogenic response to EGF or FGF. Further, these observations suggest that multiple signaling pathways are likely to be involved in growth factor and cytokine signal transduction.

IL-1 signal transduction does not involve stimulated PtdIns turnover or increases in intracellular free $\mathrm{Ca}^{2+}$ concentration (24). DAG has been shown to be produced via an alternative IL-1-mediated pathway in T lymphocytes that involves the hydrolysis of phosphatidylcholine, not PtdIns (25). While the present study confirms previous reports indicating that IL-1 does not increase inositol phosphate production $(24,25)$, we did detect an IL-1-sensitive PtdIns kinase that phosphorylated PtdIns to PtdIns4P in both intact fibroblasts and isolated membrane preparations. It is likely that the activity of PtdIns kinase(s) are modulated during stimulated PtdIns turnover so that PtdInsP pools are either maintained or increased.

The enzyme activity described here is clearly distinct from that which catalyzes the formation of PtdIns-3-phosphate and which appears to be physically associated with the platelet-derived growth factor (PDGF) receptor; PDGF is also known to stimulate PtdIns turnover in general (26). In the present instance, it appears that IL-1 affects PtdIns kinase activity independent of stimulated PtdIns turnover, and the product formed is PtdIns-4-phosphate. The relative amounts of PtdInsPs in the membrane, in addition to serving as substrate for phospholipase(s) $\mathrm{C}$, may profoundly affect the conformation of membrane proteins or alter the potential of the mem-

1. Abbreviations used in this paper: DAG, 1,2-diacylglycerol; EMEM, phosphate-free Eagle's minimum essential medium; hr, human recombinant; GroPtdIns4P, $\left[{ }^{32} \mathrm{P}\right]$ glycero-PtdInsP; IP $_{3}$, inositol 1,4,5-triphosphate; PDGF, platelet-derived growth factor; PLC, phospholipase C; PtdIns, phosphatidylinositol; PtdInsP, phosphatidylinositol-4-phosphate; PtdIns $\mathrm{P}_{2}$, phosphatidylinositol-4,5-bisphosphate. 
brane and its content of divalent cations, the influx of which often accompanies receptor-mediated cellular activation.

While the physiological significance of IL-1-mediated PtdIns phosphorylation and its role in mediating the actions of IL-1 remain unknown, our findings represent a new effector system directly modulated by IL-1. Regulation of PtdIns phosphorylation is under stringent control as evidenced by the very small amounts of phosphorylated PtdIns derivatives present in eukaryotic cells. Thus, IL-1 could play an important role in modulating the synthesis of PtdInsP, the first enzymatic step in the formation of PtdIns $P_{2}$, and/or in replenishing these important membrane phospholipids following their hydrolysis to form the second messengers inositol 1,4,5-triphosphate and diacylglycerol.

\section{Methods}

Fibroblast culture and labeling techniques. Human foreskin fibroblast cell lines were established and cultured using standard techniques. Early passage cells were seeded in 12-well flat-bottomed or $100-\mathrm{mm}$ plates and cultured in supplemented Eagle's minimum essential medium (EMEM; Whittaker Bioproducts, Walkersville, MD). The cells were incubated at $37^{\circ} \mathrm{C}$ in $95 \%$ air and $5 \% \mathrm{CO}_{2}$. After the cultures reached confluence, the medium was replaced with $0.5 \mathrm{ml}$ of fresh EMEM to which $5 \mu \mathrm{Ci}$ of $\left[{ }^{3} \mathrm{H}\right]$ myo-inositol $(47.7 \mathrm{Ci} / \mathrm{mmol}$; New England Nuclear, Boston, MA) was added. After a 72-h incubation the medium was aspirated. The cells were washed three times with $2 \mathrm{ml}$ of PBS and placed in $1 \mathrm{ml}$ of serum-free EMEM containing $10 \mathrm{mM}$ lithium chloride. After a 10-min preincubation in the presence of lithium, IL-1 $(5 \mathrm{ng} / \mathrm{ml})$ was added (control wells received no IL-1), and the incubation was allowed to proceed for $1-30 \mathrm{~min}$ at $37^{\circ} \mathrm{C}$

Inositol phosphate and PtdInsP analysis. To stop the reaction $1 \mathrm{ml}$ of ice-cold $50 \mathrm{mM} \mathrm{HCl}$ was added to each well, the cells were removed from the plate by scraping; and lipids were extracted as previously described (27). The aqueous phase of each lipid extract was combined with the corresponding culture media, diluted 10-fold with distilled water, and applied to a 1-ml AG-1 X8 column (Bio-Rad Laboratories, Rockville Centre, NY). Inositol phosphates were eluted from the columns as previously described (27).

Phosphoinositide analysis. The organic phase from each lipid extract was dried under $\mathrm{N}_{2}$ and applied to a potassium oxalate (1\%) impregnated silica gel $G$ thin-layer chromatography (TLC) plate (Analtech, Newark, DE). The plate was developed in a solvent system of chloroform/methanol/ammonium hydroxide/water (90:70:10:10 vol/ $\mathrm{vol} / \mathrm{vol} / \mathrm{vol}$ ). Radioactive peaks were detected using a digital-proportional sensing system (Bioscan, Inc., Washington, DC). PtdInsP and PtdInsP $\mathrm{P}_{2}$ were recognized by comparison with known standards.

Phosphatidylinositol kinase assay. Confluent fibroblast monolayers cultured in $100 \mathrm{~mm}$ culture dishes as above were washed twice with $10 \mathrm{ml}$ of $20 \mathrm{mM}$ Hepes buffer (pH 7.0). The final wash was aspirated and $400 \mu \mathrm{l}$ of buffer was added to the plate, and the cells were removed from the dish with a sterile cell scraper. The cells were transferred to a Dounce homogenizer and homogenized on ice. The homogenate was centrifuged for $10 \mathrm{~min}$ at $10,000 \mathrm{rpm}$ at $4^{\circ} \mathrm{C}$. The supernatant fluid was discarded and the pellet resuspended in $200 \mu \mathrm{l}$ of buffer. Typically, $25 \mu \mathrm{l}$ of the membrane preparation ( $100 \mu \mathrm{g}$ protein) was used in each assay $(50 \mu \mathrm{l}$ total volume). The reaction mixture contained $20 \mathrm{mM}$ Hepes (pH 7.0), $1 \mathrm{mM} \mathrm{MgCl} 2,10 \mu \mathrm{M}$ ATP, $1 \mu \mathrm{Ci}\left[{ }^{32} \mathrm{P}\right] \mathrm{ATP}$ (New England Nuclear; sp act 3,000 Ci/mmol; final sp act 1,300 cpm ${ }^{32} \mathrm{P} / \mathrm{pmol}$ PtdInsP assuming $1 \mathrm{~mol}$ of ${ }^{32} \mathrm{P}$ was incorporated per mol of ${ }^{32}$ PtdIns), and human recombinant (hr) IL-1 $\beta(0.25 \mathrm{ng}, 0.29 \mathrm{nM}$ final concentration; R and D Systems, Minneapolis, MN). Aliquots of the membrane preparation were placed in individual Eppendorf tubes $(0.5$ $\mathrm{ml}$ ) and warmed to $37^{\circ} \mathrm{C}$. The assay was initiated by the addition of 25 $\mu \mathrm{l}$ of reaction buffer prepared such that the final concentration of each component was as described above, and each tube was then vigorously mixed by vortex for 1-2 s. The reaction was allowed to proceed for 1 min at $37^{\circ} \mathrm{C}$ and was stopped by the addition of $500 \mu \mathrm{l}$ of methanol/
chloroform/HCl, 200:100:1. Labeled phospholipids from each reaction mixture were then extracted using the procedure described by Abraham (24). ${ }^{32} \mathrm{P}$-labeled phosphoinositides were resolved by TLC as above or as described by Jolles et al. (28) using a solvent system composed of chloroform/acetone/methanol/acetic acid/water (40:15: 13:12:8 by volume) and compared with standard PtdInsP and PtdIns $\mathrm{P}_{2}$; PtdInsP was the only radiolabeled product detected. The addition of exogenous PtdIns did not result in increased product formation, and therefore it was not added to the membrane preparation making endogenous PtdIns the sole substrate for measuring PtdIns kinase activity. In control experiments, denatured IL-1 was prepared by heating at $100^{\circ} \mathrm{C}$ for $60 \mathrm{~min}$; this treatment completely abolished its ability to stimulate PtdIns kinase activity. In other control experiments, anti-IL-1 antibody was incubated with IL-1 for $1 \mathrm{~h}$ at $37^{\circ} \mathrm{C}$ using a fivefold antibody excess required to achieve $50 \%$ IL-1 binding according to the manufacturer's instructions. All statistical analyses were performed using the Student's $t$ test for unpaired samples.

In parallel set experiments we tested the effect of IL-1 on the degradation of PtdInsP using identical assay conditions as described above except that the membranes were phosphorylated with [ $\left.{ }^{32} \mathrm{P}\right] \mathrm{ATP}$ in the presence of $\mathrm{Mg}^{2+}$ for $1 \mathrm{~min}$ before the addition of IL-1 for an additional 1 -min incubation. At the end of the second 1-min incubation period, phospholipids were extracted and analyzed as above. The difference in labeled phospholipids remaining in experimental samples was compared with control incubations without IL-1.

Deacylation and identification of phosphorylation position on the inositol ring of PtdInsP product. The PtdInsP product was analyzed by deacylation and HPLC analysis. The labeled PtdInsP product was isolated by TLC as above and recovered from the silica gel by elution with chloroform/methanol/ $0.1 \mathrm{~N} \mathrm{HCl}(1 / 2 / 0.8 \mathrm{vol} / \mathrm{vol})$. The product was treated for $50 \mathrm{~min}$ at $53^{\circ} \mathrm{C}$ with $1.8 \mathrm{ml}$ of methylamine reagent containing $5.77 \mathrm{ml}$ of $25 \%$ methylamine in water, $6.16 \mathrm{ml}$ of methanol, and $1.54 \mathrm{ml}$ of 1-butanol. After lyophilization, the sample was resuspended in $1.8 \mathrm{ml}$ of water. To separate the water-soluble [ $\left.{ }^{32} \mathrm{P}\right] \mathrm{glycero}-$ PtdInsP (GroPtdInsP) products from unreacted PtdInsP, the sample was extracted twice with an equal volume of 1-butanol/light petroleum ether/ethyl formate (20:4:1). The extracted aqueous phase was lyophilized and analyzed by HPLC. $\left[{ }^{3} \mathrm{H}\right] \mathrm{GroPtdIns} 4 \mathrm{P}$ was prepared by deacylation of standard $\left[{ }^{3} \mathrm{H}\right] \mathrm{PtdIns}-4-$ phosphate (New England Nuclear) and was analyzed by HPLC alone and was added as an internal standard for comparison with the product formed in vitro.

HPLC analysis of phosphoinositides. Anion-exchange HPLC was performed on a Whatman 5 Partisphere SAX column. The sample was loaded in water, the column washed for $10 \mathrm{~min}$ with water and eluted with a linear gradient over $50 \mathrm{~min}$ from 0 to $0.252 \mathrm{M}\left(\mathrm{NH}_{4}\right)_{2} \mathrm{HPO}_{4}, \mathrm{pH}$ 3.8 , at $1 \mathrm{ml} / \mathrm{min}$. Fractions of $0.5 \mathrm{ml}$ were collected and counted for radioactivity by liquid scintillation.

\section{Results}

The effect of IL-1 $1 \beta$ on inositol phosphate production in human fibroblasts. Previous studies examining signal transduction mechanisms involved in IL-1-mediated T cell activation (24) showed that IL-1 neither induced the production of inositol phosphates nor resulted in increased intracellular free calcium concentrations, suggesting that the IL-1 receptor was not associated with the activation of PtdIns-specific PLC. We performed several separate experiments using human foreskin fibroblasts labeled with $\left[{ }^{3} \mathrm{H}\right]$ myo-inositol which were then treated with hrlL-1 for 1-30 min. No statistically significant differences were observed in inositol phosphate production in IL-1-treated cells compared with control cells at any of the time points tested (data not shown). All experiments were performed in the presence of $10 \mathrm{mM}$ lithium chloride, an inhibitor of inositol monophosphatase (15), which would favor inositol phosphate accumulation.

We expanded the experiments described above to include an analysis of labeled products in the organic phase of extracts 
obtained from the above cells. We observed an increase in labeled PtdInsP in those cells treated with IL-1 when compared with controls. Under the conditions described, label associated with PtdInsP accounted for $\sim 20 \%$ of the total counts recovered in the organic phase, the remainder was found in $\left[{ }^{3} \mathrm{H}\right]-$ PtdIns. In four separate experiments, we observed an average increase in labeled PtdInsP of $6.5 \% \pm 0.8 \%$ (data not shown). This observation suggested that IL-1 affected the accumulation of PtdInsP in the absence of stimulated PtdIns turnover. Such a result could be explained by the stimulation of an IL-1-mediated PtdIns kinase activity functioning independently of stimulated PtdIns turnover. This hypothesis was tested as described in the following sections.

IL-1 stimulates PtdIns kinase activity in vitro. The finding that IL-1 stimulated the accumulation of phosphoinositides in $\left[{ }^{3} \mathrm{H}\right]$ myo-inositol-labeled cells led us to test the ability of IL-1 to stimulate the phosphorylation of endogenous PtdIns in vitro using a fibroblast membrane preparation. We used an assay that measured the phosphorylation of PtdIns by incubating the membranes with $\left[{ }^{32} \mathrm{P}\right] \mathrm{ATP}$ in the presence of $\mathrm{Mg}^{2+}$ ion with or without IL-1. As shown in Fig. 1, incubation of membranes with [ $\left.{ }^{32} \mathrm{P}\right] \mathrm{ATP}$ in the presence of $\mathrm{Mg}^{2+}$ resulted in the production of a basal level of label in PtdInsP; no labeled PtdIns $\mathrm{P}_{2}$ was detected in these assays. The addition of calcium to the reaction mixture reduced the net accumulation of label in PtdInsP in the presence of $\mathrm{Mg}^{2+}$ ion; this could either be attributed to a direct inhibition of the enzyme by calcium as previously described (28) or a calcium-dependent increase in PtdIns-specific PLC activity. In identical assays in which IL-1 was added to the reaction mixture, no increase in PtdInsP formation was observed in the absence of added $\mathrm{Mg}^{2+}$. However, in the presence of $1 \mathrm{mM} \mathrm{Mg}^{2+}$, IL-1 significantly stimulated the accumulation of labeled PtdInsP over that amount detected in incubations containing $\mathrm{Mg}^{2+}$ alone or denatured IL-1. Again, when $\mathrm{Ca}^{2+}$ was added to the reaction mixture, labeled PtdInsP accumulation was reduced.

To demonstrate that the response was specific for IL-1 we treated hrIL- $1 \beta$ with specific neutralizing antisera $(R$ and $D$

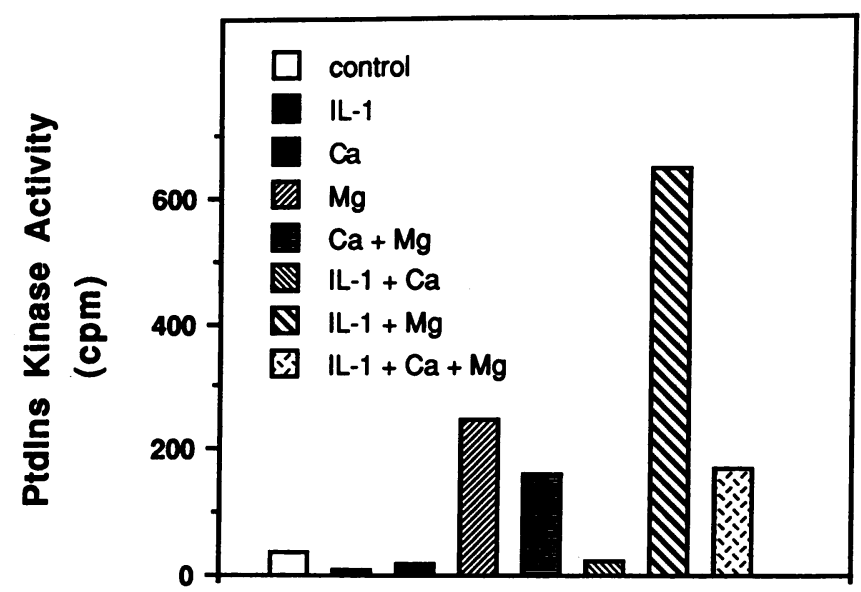

Figure 1. IL-1 $\beta$ stimulates PtdIns kinase activity in vitro. PtdIns kinase activity was measured using isolated human fibroblast membranes as described (see Methods). PtdIns kinase activity is expressed as courts per minute PtdInsP formed during a 1-min assay. IL-1 $\beta(0.25 \mathrm{ng})$, calcium $(1 \mathrm{mM})$, and magnesium $(1 \mathrm{mM})$ were present as indicated. The data represent mean values from duplicate assays in three separate experiments. Standard deviations were $<5 \%$ of the mean.
Systems). This treatment completely abolished the ability of IL-1 to stimulate PtdIns kinase activity compared with controls (antibody alone and no additions). We also tested the ability of heat-denatured IL-1 $\left(100^{\circ} \mathrm{C}\right.$ for $\left.60 \mathrm{~min}\right)$ to stimulate PtdIns kinase activity. In five separate experiments heat-denatured IL1 failed to stimulate PtdIns kinase activity compared with negative controls (no additions) and positive controls (nondenatured IL-1) with a $P$ value $<0.05$.

One possible explanation for the apparent stimulatory effect of IL-1 on PtdInsP accumulation could be that IL-1 inhibits the breakdown of PtdInsP, presumably by inhibiting the - PLC-mediated degradation of PtdInsP. Therefore, we labeled endogenous PtdInsP with [ $\left.{ }^{32} \mathrm{P}\right] \mathrm{ATP}$ for $1 \mathrm{~min}$ before the addition of IL-1 (total cpm incorporated, $1,717 \pm 28$ ). IL-1 had no effect on PtdInsP degradation during the subsequent 1-min incubation in the absence of calcium $(1,736 \pm 97 \mathrm{cpm})$. Calcium alone accounted for a $32 \%$ decrease in $\left[{ }^{32} \mathrm{P}\right] \mathrm{Ptd}$ InsP $(1,185 \pm 52 \mathrm{cpm})$, which was essentially not altered by the addition of IL- 1 to the reaction mixture $(1,133 \pm 5 \mathrm{cpm})$. As a positive control, phosphorylated membranes were incubated as above with PDGF, a known activator of PLC. Label in PtdInsP decreased by over $49 \%$ compared with controls $(885 \pm 5 \mathrm{cpm})$. These results indicate that while there is a $\mathrm{Ca}^{2+}$-mediated decrease in phosphoinositide labeling, IL-1 does not affect the degradation of PtdInsP either in the presence or absence of $\mathrm{Ca}^{2+}$. Thus, the accumulation of label in PtdInsP in response to IL-1 does not appear to be due to IL-1-mediated inhibition of PtdInsP degradation and is consistent with previous studies indicating that IL-1 is not involved in stimulated PtdIns hydrolysis/turnover.

Identification of the phosphoinositide product. The PtdIns phosphate product obtained by incubating fibroblast membranes with [ $\left.{ }^{32} \mathrm{P}\right] \mathrm{ATP}$ as phosphate donor and standard PtdIns4P (New England Nuclear) were deacylated, and the resulting glycerophosphoinositol phosphates (GroPtdInsPs) were separated in an anion-exchange HPLC optimized for resolution of GroPtdInsP isomers. Fig. $2 A$ shows the elution profile of standard $\left[{ }^{3} \mathrm{H}\right] \mathrm{GroPtdIns} 4 \mathrm{P}$ from the column, with a majority of the counts eluted in fraction number 85 (a retention time of $42.5 \mathrm{~min}$ ). Fig. $2 \mathrm{~B}$ shows the elution of ${ }^{32} \mathrm{P}$-labeled product obtained by incubating membranes with $\left[{ }^{32} \mathrm{P}\right] \mathrm{ATP}$ which was then processed as described above. The retention time of the resulting product was identical to that of standard GroPtdIns4P. The smaller peak with a slightly longer retention time is unidentified. Fig. $2 C$ shows that when standard $\left[{ }^{3} \mathrm{H}\right]-$ GroPtdIns4P and the ${ }^{32} \mathrm{P}$ produce obtained from the in vitro reaction mixture are co-chromatographed, their elution profiles are identical. These data clearly demonstrate that the product formed by human fibroblasts is PtdIns4P, not the recently described PtdIns-3-phosphate produced by fibroblasts in response to PDGF $(26,29)$.

Dose-response curve for IL-1-stimulated PtdIns kinase activity. The ability of IL-1 to stimulate PtdIns kinase activity in vitro was tested over a concentration range of $10^{-14}$ to $10^{-9} \mathrm{M}$ IL-1. The data presented in Fig. 3 show that PtdIns kinase activity is stimulated as a function of increasing IL-1 concentration, and at all concentrations tested, a 1-min preincubation of IL-1 with the membranes resulted in greater PtdIns kinase activity. No stimulation of PtdIns kinase activity could be detected within $1 \mathrm{~min}$ at $10^{-13} \mathrm{M}$ IL-1, but an increase in enzymatic activity of $8.7 \%$ without IL-1 preincubation and $28.2 \%$ with a 1 -min preincubation period could be measured at $10^{-12}$ M IL-1. PtdIns kinase activity continued to increase as a func- 


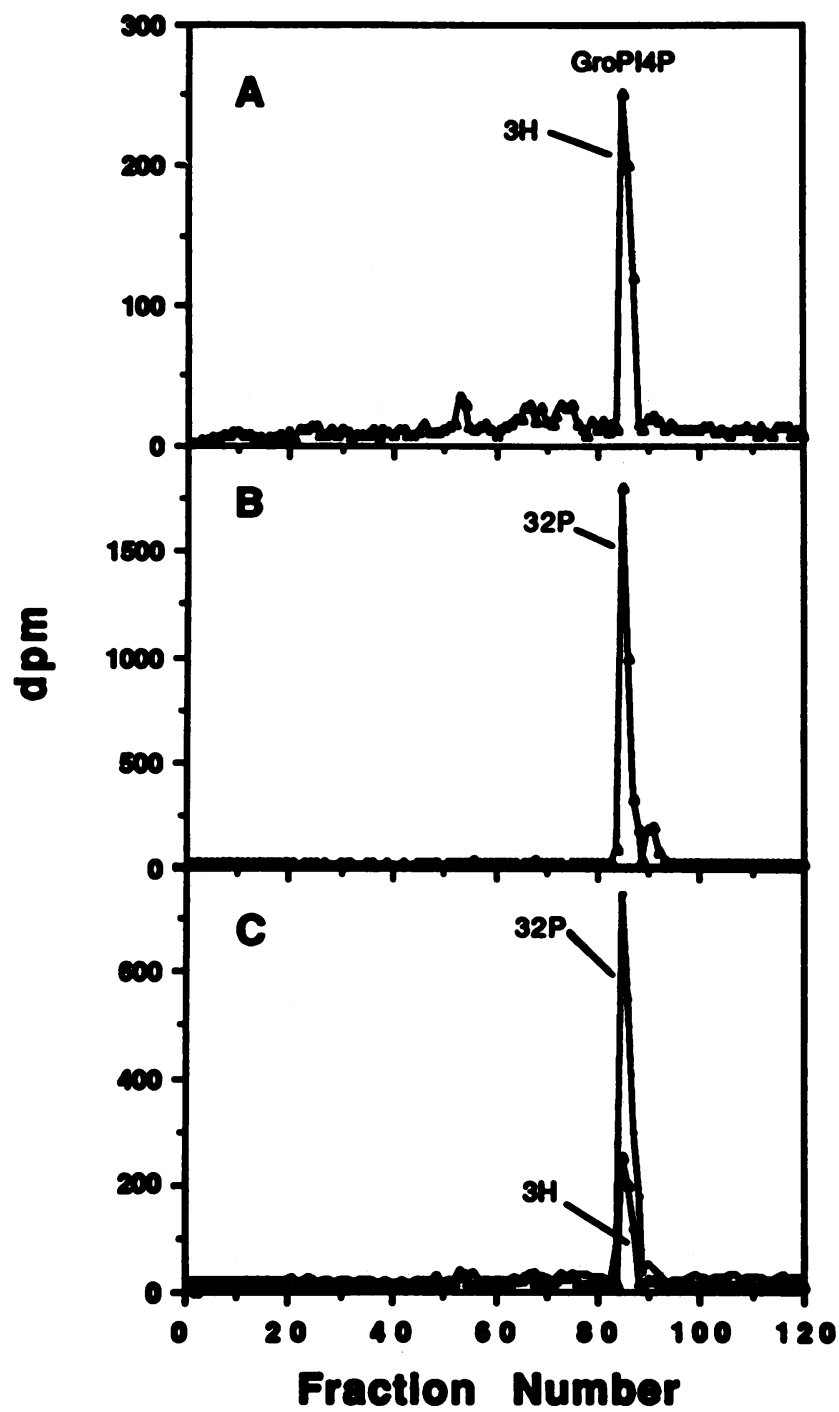

Figure 2. Anion-exchange HPLC analysis of the deacylated PtdInsP product. Either standard $\left[{ }^{3} \mathrm{H}\right] \mathrm{PtdIn} 4 \mathrm{P} \mathrm{P}$ or the radioactive phosphoinositide produced by human fibroblasts was treated as described in Methods. $(A)$ The elution profile of the deacylation produce obtained from $\left[{ }^{3} \mathrm{H}\right] \mathrm{PtdIns} 4 \mathrm{P}$. $(B)$ Elution profile of the $\left.{ }^{32} \mathrm{P}\right]$ deacylation product extracted from an in vitro reaction mixture. $(C)$ The elution profile of a mixture of $\left[{ }^{3} \mathrm{H}\right](A)$ and $\left[{ }^{32} \mathrm{P}\right] \mathrm{GroPtdInsP}$ $(B)$ products chromatographed as described.

tion of IL-1 concentration such that half-maximal activity was attained at $\sim 10^{-10} \mathrm{M} \mathrm{IL-1}$ when compared with the degree of stimulation reached in the presence of $10^{-9} \mathrm{M}$ IL-1, the highest concentration of cytokine tested in these experiments. These data clearly show that IL- $1 \beta$ stimulates PtdIns kinase activity in a dose-dependent manner within the physiological concentration range for IL- 1 and that preincubation of IL-1 with membranes for $1 \mathrm{~min}$ before the addition of labeled substrate resulted in increased PtdIns kinase activity.

Time course of IL-1-stimulated PtdIns kinase activity. Data obtained from time-course experiments are shown in Fig. 4. Fig. $4 \mathrm{~A}$ shows the total amount (cpm) of PtdIns4P formed at the times indicated ( $10 \mathrm{~s}$ was the earliest time point taken) in the presence and absence of IL-1. Assays were performed as described in the legend to Fig. 4 using a single membrane preparation divided such that each reaction mixture received an

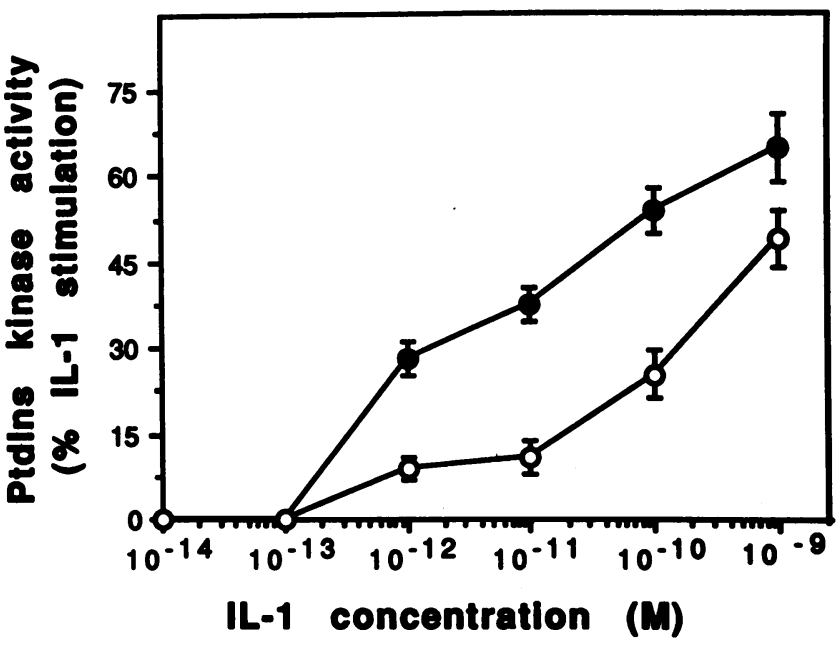

Figure 3. Dose-response curve for IL-1-stimulated PtdIns kinase activity in vitro. PtdIns kinase assays were performed as described in Methods. All data points represent the mean \pm SD from duplicate assays in two separate experiments. IL-1 was either added at the indicated concentrations at time zero with $\left.{ }^{32} \mathrm{P}\right] \mathrm{ATP}(\mathrm{O})$, or $1 \mathrm{~min}$ before the addition of $\left[{ }^{32}\right.$ P]ATP $(\bullet)$.

identical amount of protein. Under these conditions, the reaction rate is linear for the first minute, after which time the rate of product formation decreases somewhat both in the presence and absence of IL-1. This decrease is most likely due to depletion of ATP as previously shown (27) and not to limiting amounts of PtdIns, as addition of excess PtdIns to the reaction mixture did not affect the linear nature of the reaction. At all time points tested, the kinase activity in the presence of IL-1 was greater than in assays not containing IL-1. Fig. $4 B$ shows the same data when control basal kinase activity in the absence of IL- 1 is subtracted from values in the presence of IL-1. This figure clearly shows that the rate of product formation due to the IL-1-stimulated component of the total kinase activity detected in these samples was linear during the 5-min assay.

\section{Discussion}

The biochemical mechanisms involved in the intracellular transmission of IL-1 signals are unclear. One mechanism whereby growth factor/cytokine receptors and other stimuli exert their respective effects is through the stimulation of PtdIns turnover (30-32). Altered phosphorylation and turnover of PtdIns have also been demonstrated in cells transformed by DNA and RNA tumor viruses $(29,33-37)$, demonstrating the importance of this pathway in modulating the responses of cells to external stimuli. Some investigators have examined the effects of IL-1 on PtdIns turnover and have concluded that IL-1 neither affects PtdIns turnover nor increases the intracellular concentration of calcium (24). Others have shown that IL-1 may, however, stimulate the production of DAG by a pathway not involving PtdIns turnover, but instead, phosphatidylcholine or phosphatidyl-ethanolamine hydrolysis $(25,37)$. Metabolism of these alternate phospholipid substrates is mediated by putative PLC enzymes distinct from the wellcharacterized PtdIns-specific PLC.

In a search for potential signal transduction pathways for the IL-1 receptor system, some have suggested that IL-1 may activate a tyrosine kinase activity (38). It has not been established whether this kinase activity is intrinsic to the IL-1 recep- 


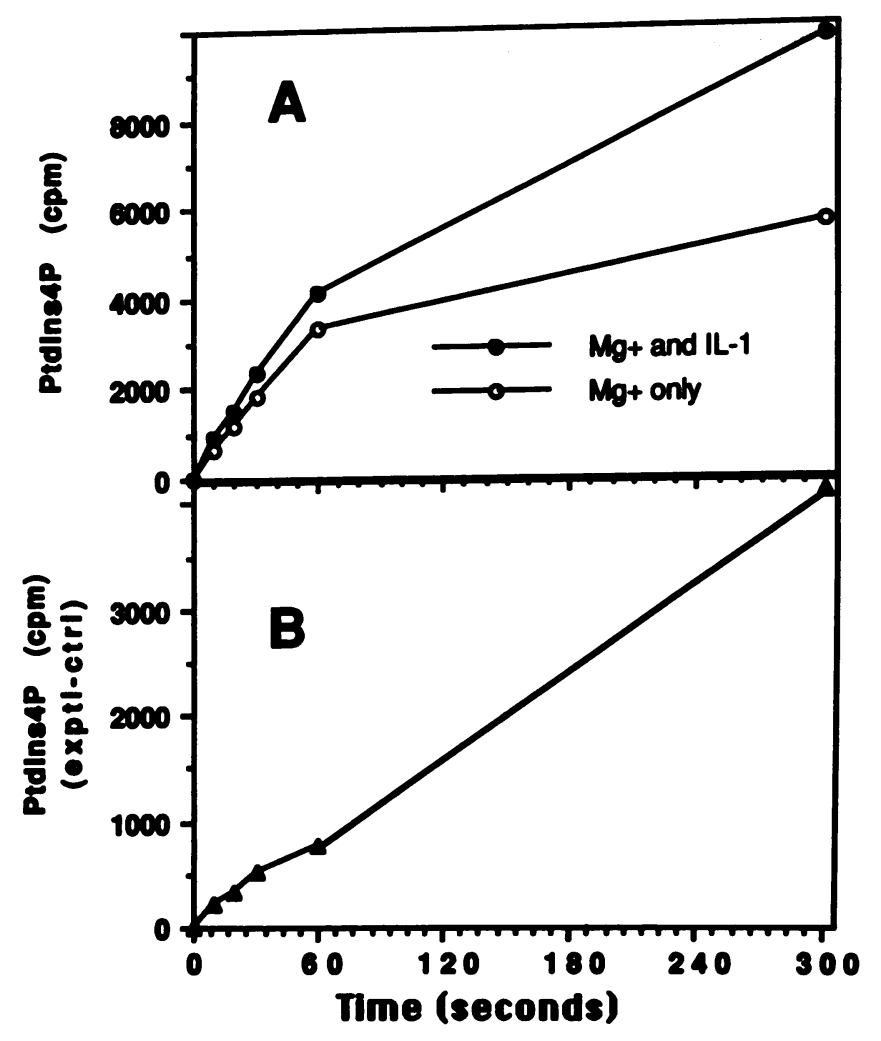

Figure 4. Time course of IL-1-stimulated PtdIns kinase activity. All assays were performed as described in Methods, except that sufficient membrane material and buffer containing $5 \mathrm{mM} \mathrm{Mg}^{2+}$ was placed in a single test tube (one each for control [no IL-1] and experimental [plus IL-1] assays). Each sample was warmed to $37^{\circ} \mathrm{C}$ for $5 \mathrm{~min}$, after which time either buffer or IL-1 was added to each tube for an additional $15 \mathrm{~s}$. The reaction was initiated by the addition of $\left.{ }^{32} \mathrm{P}\right] \mathrm{ATP}$ $(3 \mu \mathrm{Ci} / 50 \mu \mathrm{l})$. At the times indicated a $50-\mu \mathrm{l}$ aliquot was removed from each tube and immediately placed in the organic extraction solution. PtdIns4 $\left[{ }^{32} \mathrm{P}\right]$ production was determined by TLC. $(A)$ Product formed as a function of time in the presence and absence of IL-1. $(B)$ The difference between the amount of PtdInsP produced in the presence of IL-1 minus the amount of product formed in the absence of IL-1 as a function of time.

tor as described for growth factor receptors such as PDGF (38), EGF, insulin, and colony stimulating factor 1, which are themselves tyrosine kinases (39). In a variety of systems in which receptor ligation results in the stimulation of tyrosine kinase activity, there appears to be a positive correlation with respect to the concomitant stimulation of PtdIns kinase activity (40). Such observations suggest that either the PtdIns kinase is a substrate for receptor-stimulated tyrosine kinase (40) or that PtdIns kinase activity is regulated by the auto-phosphorylation of the receptor (26).

The present data confirm previous studies indicating that IL-1 does not stimulate the hydrolysis of PtdIns in human fibroblasts. We did find, however, that IL-1 stimulated the accumulation of PtdIns-4-P, in contrast to the PtdIns-3-P which has been shown to be produced by fibroblasts in response to PDGF (26). Pike et al. (41) have shown increased PtdInsP kinase activity in polymorphonuclear cells in response to chemoattractants, which converts PtdInsP to PtdInsP $\mathrm{P}_{2}$ without the activation of PtdIns kinase activity. Together, such findings demonstrate the stringent regulation of specific enzymes involved in the synthesis of specific phosphoinositides from PtdIns. These data further suggest that multiple signals may be required to activate the individual kinases required for the production of PtdIns $\mathrm{P}_{2}$. Our findings also indicate that IL-1 stimulates PtdIns kinase activity without affecting the PLC-mediated hydrolysis of PtdIns-phosphates, unlike chemoattractants that appear to affect both the synthesis and degradation of phosphoinositides (41). While the present findings are consistent with those who have shown that IL-1 does not stimulate increased inositol phosphate production $(24,25)$, the data suggest that IL-1 may in fact play a critical role in PtdIns turnover by regulating substrate availability for the phospholipase(s) involved in second messenger production.

The concentrations of IL-1 required to see the stimulation of PtdIns kinase activity in vitro are within the range expected for mediation of the biological effects of IL- 1 in intact cells. The fact that we can observe stimulated PtdIns kinase activity at $10^{-12} \mathrm{M}$ within $1 \mathrm{~min}$ in a fibroblast membrane preparation clearly demonstrates that IL-1 receptors have a high affinity for IL- 1 and that the enzyme is most likely in very close association with the receptor, if not physically associated with it as has been shown by others for the PDGF receptor (26). O'Neill et al. (42) have recently demonstrated that low concentrations of IL-1, in the range of 0.1 to $100 \mathrm{ng} / \mathrm{ml}$, stimulated increased GTP binding and hydrolysis in membranes of a murine cell line (EL4) known for high IL-1 receptor expression. Rossoff et al. (25) and Kester et al. (37) have also both recently described rapid (within minutes) effects of low doses of IL-1 on phospholipid metabolism in T cells and cultured rat mesangial cells, respectively.

The point that in many instances the physiological effects of IL-1 require long periods of time to manifest themselves, hours or days, is of particular interest in view of the relative rapidity of the types of specific responses to IL-1 described above. Such delayed physiological responses suggest that the production of second messengers that act to multiply the effects of IL-1 may be more important than the initial occupancy of high levels of receptor. Some studies with Jurkat cells suggest that responses to IL- 1 can be seen even in the absence of measurable IL-1 binding (25). One of the main reasons that the biochemical mechanisms of IL-1 action, especially early events, have eluded detection thus far is quite likely due to the fact the signals are subtle and difficult to detect. But, over a period of time, the signals become amplified via the generation of a variety of second messenger molecules.

In summary, our findings demonstrate that IL-1 induces a rapid increase in the accumulation of PtdInsP and not its hydrolysis. Since the rapid, transient increase in the hydrolysis of PtdInsP(s) is the hallmark of many receptor-mediated signal transduction systems, the regulation of PtdInsP production by IL-1 could dramatically alter, both quantitatively and qualitatively, the second messenger molecules formed as a result of the activation of receptors coupled to PLC which mediate the hydrolysis of phosphorylated derivatives of PtdIns. Thus, while some argue that IL-1 has no effect on PtdIns turnover, our data suggest that IL-1 may affect PtdIns turnover at the level of substrate availability. In this way, IL-1 could potentially affect the production of a variety of second messenger molecules derived from the hydrolysis of phosphoinositides in response to agonists that do induce phosphoinositide turnover. An alteration in the relative amounts of PtdIns, PtdInsP, and PtdInsP in the absence of stimulated PtdIns turnover could also modify membrane conformation and as such affect the ability of the cell to respond to a wide variety of external stimuli. 
Studies are now underway to determine the mechanism by which IL-1 stimulates PtdIns kinase activity and the role that other cytokines/agonists may play in regulating PtdIns turnover. Regardless of the mechanism, the studies described here show a direct, IL-1-mediated stimulation of an enzyme that is involved in regulating the production of phosphorylated PtdIns derivatives. These derivatives then serve as substrates for the production of second messenger molecules. In this way, IL-1 may serve to restore levels of these substrates following their hydrolysis by phospholipase $\mathrm{C}$ or other hydrolytic enzymes.

\section{Acknowledgments}

We thank Phyllis Mikula for help in preparation of the manuscript and Dr. John Fain for suggestions and critically reviewing the manuscript.

These studies were supported by research funds from the Veterans Affairs Medical Center, University Physicians Foundation, and by grants AR-39166, AR-26034 from the National Institutes of Health (NIAMS).

\section{References}

1. Dinarello, C. A. 1986. Interleukin-1: amino acid sequences, multiple biolog ical activities and comparison with tumor necrosis factor (cachectin). Year Im munol. 2:68-86.

2. Dinarello, C. A., and N. Savage. 1989. Interleukin-1 and its receptor. Crit. Rev. Immunol. 9:1-20.

3. Lomedico, P. T., C. P. Gubler, M. Hellman, J. G. Dukovich, Y.-C. E. Giri, K. Pan, R. Collier, R. Deminow, O. A. Chua, and S. B. Mizel. 1984. Cloning and expression of a murine interleukin-1 cDNA. Nature (Lond.). 312:458-462.

4. March, C. J., B. Mosely, A. Larsen, D. P. Cerreti, G. Braedt, V. Price, S Gillis, C. S. Henney, S. R. Kronheim, K. Grabstein, P. J. Conlon, T. P. Hopp, and D. Cosman. 1985. Cloning, sequence and expression of two distinct human interleukin-1 complementary DNAs. Nature (Lond.). 315:641-644.

5. Auron, P. E., A. C. Webb, L. J. Rosenwasser, S. F. Mucci, A. Rich, S. M Wolff, and C. A. Dinarello. 1985. Nucleotide sequence of human monocyte Interleukin-1 precursor cDNA. Proc. Natl. Acad. Sci. USA. 81:7907-7911.

6. Dower, S. K., S. M. Call, S. Gillis, and D. L. Urdal. 1986. Similarity between the Interleukin-1 receptors on a murine T-lymphoma cell line and on a murine fibroblast cell line. Proc. Natl. Acad. Sci. USA. 83:1060-1065.

7. Dower, S. K., S. R. Kronheim, C. J. March, P. J. Conlon, T. P. Hopp, S Gillis, and D. L. Urdal. 1985. Detection and characterization of high affinity plasma membrane receptors for human interleukin-1. J. Exp. Med. 162:501515.

8. Horuk, R. J., J. J. Huang, M. Covington, and R. C. Newton. 1987. A biochemical and kinetic analysis of the interleukin-1 receptor. Evidence for differences in molecular properties of IL-1 receptors. J. Biol. Chem. 262:1627516278.

9. Rhyne, J. A., S. B. Mizel, R. G. Taylor, M. Chedid, and C. E. McCall. 1988. Characterization of the human interleukin-1 receptor on human polymorphonuclear leukocytes. Clin. Immunol. Immunopathol. 48:354-361.

10. Chedid, M., F. Shirakawa, P. Naylor, and S. B. Mizel. 1988. Characterization of the signal-transduction pathway for IL-1 mediated human rheumatoid synovial cell activation. FASEB (Fed. Am. Soc. Exp. Biol.) J. 2:165a. (Abstr.)

11. Chin, J., E. Rupp, P. M. Cameron, K. L. MacNaul, P. A. Lotke, M. J. Tacci, J. A. Schmidt, and E. K. Bayne. 1988. Identification of high-affinity receptor for Interleukin-1 alpha and Interleukin-1 beta in cultured human rheumatoid synovial cells. J. Clin. Invest. 82:420-426.

12. Bird, T. A., and J. Saklatvala. 1986. Identification of a common class of high-affinity receptors for both types of porcine Interleukin-1 on connective tissue cells. Nature (Lond.). 324:263-266.

13. Shirakawa, F., U. Yamashita, M. Chedid, and S. B. Mizel. 1988. cAMP-an intracellular second messenger for Interleukin-1. Proc. Natl. Acad. Sci. USA. 85:8281-8286.

14. Berridge, M. J. 1987. Inositol triphosphate and diacylglycerol: two interacting second messengers. Annu. Rev. Biochem. 56:159-193.

15. Berridge, M. J. 1984. Inositol triphosphate and diacylglycerol as second messengers. Biochem. J. 220:345-360.

16. Hokin, L. E. 1985. Receptors and phosphoinositide-generated second messengers. Annu. Rev. Biochem. 54:204-235.
17. Kikkawa, U., and Y. Nishizuka. 1986. The role of protein kinase $C$ in transmembrane signaling. Annu. Rev. Cell. Biol. 2:149-178.

18. Paris, S., and J. Pouysségur. 1986. Pertussis toxin inhibits thrombin-induced activation of phosphoinositide hydrolysis and $\mathrm{Na}^{+} / \mathrm{H}^{+}$exchange in hamster fibroblasts. EMBO (Eur. Mol. Biol. Organ.) J. 5:55-60.

19. Paris, S., and J. Pouysségur. 1987. Further evidence for a phospholipase C-coupled G protein in hamster fibroblasts. J. Biol. Chem. 262:1970-1976.

20. Paris, S., J. C. Chambard, and J. Pouysségur. 1987. Coupling between phosphoinositide breakdown and early mitogenic events in fibroblasts. J. Biol. Chem. 262:1977-1983.

21. L'Allemain, G., and J. Pouysségur. 1986. EGF and insulin action in fibroblasts: Evidence that phosphoinositide hydrolysis is not an essential mitogenic signalling pathway. FEBS (Fed. Eur. Biochem. Soc.) Lett. 197:344-348.

22. Magnaldo, I., G. L'Allemain, J. C. Chambard, M. Moenner, D. Barritault, and J. Pouysségur. 1986. The mitogenic signaling pathway of fibroblast growth factor is not mediated through polyphosphoinositide hydrolysis and protein kinases C activation in hamster fibroblasts. J. Biol. Chem. 261:16916-16922.

23. Besterman, J. M., S. P. Watson, and P. Cuatrecasas. 1986. Rapid formation of diacylglycerol from phosphatidylcholine: a pathway for generation of a second messenger. J. Biol. Chem. 261:723-727.

24. Abraham, R. T., S. N. Ho, T. J. Barna, and D. J. McKean. 1987. Transmembrane signaling during interleukin-1-dependent $\mathrm{T}$ cell activation. J. Biol. Chem. 262:2719-2728.

25. Rosoff, P. M., N. Savage, and C. A. Dinarello. 1988. Interleukin-1 stimulates diacylglycerol production in T-lymphocytes by a novel mechanism. Cell. 54:73-81.

26. Coughlin, S. R., J. A. Escobedo, and L. T. Williams. 1989. Role of phosphatidylinositol kinase in PDGF receptor signal transduction. Science (Wash. DC). 243:1191-1193.

27. Emilsson, A., and R. Sundler. 1984. Differential activation of phosphatidylinositol deacylation and a pathway via diphosphoinositide in macrohages responding to zymosan and ionophore A23187. J. Biol. Chem. 259:3111-3116.

28. Jolles, J., H. Zwiers, A. Dekkes, K. W. A. Wirtz, and W. H. Crispen. 1981. Corticotropin-(1-24)-tetracosapeptide affects protein phosphorylation and polyphosphoinositide metabolism in rat brain. Biochem. J. 194:283-291.

29. Macara, I. G., G. V. Marinetti, and P. C. Balduzzi. 1984. Transforming protein of avian sarcoma virus UR2 is associated with phosphatidylinositol kinase activity: possible role in tumorigenesis. Proc. Natl. Acad. Sci. USA. 81:27282732.

30. Habenicht, A. J. R., J. A. Glomset, W. C. King, C. Nist, C. D. Mitchell and R. Ross. 1981. Early changes in phosphatidylinositol and arachidonic acid metabolism in quiescent Swiss 3T3 cells stimulated to divide by platelet-derived growth factor. J. Biol. Chem. 256:12329-12335.

31. Berridge, M. J., J. P. Heslop, R. F. Irvine, and K. D. Brown. 1984. Inosito triphosphate formation and calcium mobilization in Swiss 3T3 cells in response to platelet-derived growth factor. Biochem. J. 222:195-201.

32. Whitman, M., D. R. Kaplan, B. S. Schaffhausen, L. Cantley, and T. M. Roberts. 1985. Association of phosphatidylinositol kinase activity with polyoma middle-T competent for transformation. Nature (Lond.). 315:239-242.

33. Fry, M. J., A. Gebhardt, P. J. Parker, and G. Foulkes. 1985. Phosphatidylinositol turnover and transformation of cells by Abelson murine leukemia virus. EMBO (Eur. Mol. Biol. Organ.) J. 4:3173-3178.

34. Kaplan, D. R., M. Whitman, B. Schaffhausen, L. Raptis, R. L. Garcea, D. Pallas, T. M. Roberts, and L. Cantley. 1986. Phosphatidylinositol metabolism and polyoma-mediated transformation. Proc. Natl. Acad. Sci. USA. 83:3624 3628 .

35. Jackowski, S., C. W. Rettinmeier, C. J. Sherr, and C. O. Rock. 1986. A guanine nucleotide-dependent phosphatidylinositol 4,5-diphosphate phospholipase $\mathrm{C}$ in cells transformed by the v-fms and v-fes oncogenes. J. Biol. Chem 261:4978-4985.

36. Kato, M. S. Kawai, and T. Takenawa. 1987. Altered signal transduction in erbB-transformed cells. J. Biol. Chem. 262:5696-5704.

37. Kester, M., M. S. Simonson, P. Mene, and J. R. Redor. 1989. Interleukin1 generates transmembrane signals from phospholipids through novel pathways in cultured rat mesangial cells. J. Clin. Invest. 83:718-723.

38. Lovett, D. H., M. Martin, S. Bursten, M. Szamel, and K. Resch. 1989. Interleukin-1 and the glomerular mesangium. III. IL-1-dependent stimulation of mesangial cell protein kinase activity. Kidney Int. 34:26-35.

39. Bishop, J. M. 1985. Viral oncogenes. Cell. 42:23-38

40. Kaplan, D. R., M. Whitman, B. Schauffhausen, D. C. Pallas, M. White, L Cantley, and T. M. Roberts. 1987. Common elements in growth factor stimulation and oncogenic transformation: 85 kd phosphoprotein and phosphatidylinositol kinase activity. Cell. 50:1021-1029.

41. Pike, M. C., M. E. Bruck, C. Arndt, and C. S. Lee. 1990. Chemoattractants stimulate phosphatidylinositol-4-phosphate kinase in human polymorphonuclear leukocytes. J. Biol. Chem. 265:1866-1873.

42. O'Neill, L. A., T. A. Bird, A. J. H. Gearing, and J. Saklatvala. 1990 Interleukin-1 signal transduction: increased GTP binding and hydrolysis in membranes of a murine thyoma line (EL4). J. Biol. Chem. 265:3146-3152. 